\title{
O imaginário enquanto dinamizador da identidade profissional docente: uma interlocução com as ações realizadas
}

\author{
The imaginary as a dynamizer of professional teacher identity: a dialogue with the \\ actions taken
}

\author{
Shirlei Alexandra Feter ${ }^{1 *}$, Denise Regina Quaresma da Silva1 ${ }^{2}$
}

\begin{abstract}
RESUMO
O presente texto apresenta como objetivo as concepções sobre a constituição do imaginário a partir do processo dialógico com a constituição da identidade profissional. Com isso, a metodologia conta com o embasamento teórico realizado através de revisão de literatura, por meio de artigos científicos, teses, dissertações e livros de renomados autores. A partir dos resultados da pesquisa, foi possível identificar que a subjetividade, isto é, a identidade docente, está caracterizada pelas suas ações nas relações pedagógicas, constituídas pelos processos dialógicos com temáticas emergentes. As considerações compreendem as características que compõem da competência para a identidade docente da educação num contexto prático, social e cultural, isto é, a partir do imaginário é possível constituir-se, desconstruir-se e reconstruir-se enquanto profissional docente.
\end{abstract}

Palavras-chave: Imaginário; Docência; Identidade; Profissionalização.

\begin{abstract}
The present text presents as objective the conceptions about the constitution of the imaginary from the dialogic process with the constitution of the professional identity. Thus, the methodology has a theoretical basis carried out through literature review, through scientific articles, theses, dissertations and books by renowned authors. From the research results, it was possible to identify that subjectivity, that is, the teaching identity, is characterized by its actions in pedagogical relations, constituted by dialogic processes with emerging themes. The considerations include the characteristics that make up the competence for the teaching identity of education in a practical, social and cultural context, that is, based on the imagination it is possible to constitute, deconstruct and reconstruct oneself as a teaching professional.
\end{abstract}

Keywords: Imaginary; Teaching; Identity; Professionalization.

\section{INTRODUÇÃO}

Durante o estudo teceu-se algumas considerações sobreo imaginário e os saberes constituídos em conhecimentos, que o/a professor/a adquire, sobre os quais possibilitam

\footnotetext{
${ }^{1}$ Universidade La Salle, Bolsista Capes 1. *fettershirlei@gmail.com

${ }^{2}$ Universidade La Salle 2
} 
o processo de constituição da sua identidade profissional. Os estudos que envolvem o Imaginário social docente partem dos pressupostos de que a constituição da identidade docente contempla o desenvolvimento humano pessoal e profissional. Em sentido teórico os fundamentos estão baseados em: Castoriadis,1982; Müller, 2005; Durand, 1989; Barbier, 1994; Baczko, 1984; Rey, 2003.

Teorias que fundamentam a discussão sobre os sentidos atribuídos à identidade profissional docente externam o diálogo entre: Nóvoa e Gonçalves 2000; Freire 1996; Bergamaschi e Almeida, 2013.

Ao apresentar a metodologia de uma investigação qualitativa, para tal, realizou-se um estudo bibliográfico, o qual foi construído com base no objetivo de descrever os conceitos de imaginário a construir a identidade profissional docente.

Nos resultados, há discussão apresentada pela narrativa do conceito de imaginário e a identidade profissional docente, problematizando as temáticas emergentes à atuação docente. É desta forma que se permite analisar as ações, oportunizar e conhecer as diferentes concepções e conceitos construídos em âmbito coletivo, que organizam o imaginário em outras tantas situações e segmentos, que fazem parte do processo de formação e constituição da identidade profissional docente.

Ao realizar uma análise sobre a constituição do imaginário e a identidade profissional docente, a partir do processo dialógico sobre a identidade profissional, Tardif (2011), enfatiza que a identidade profissional está relacionada à constituição docente. Por isso, a urgência de descrever os conceitos de imaginário a construir a identidade profissional docente.

Diante disso, proferiu-se as considerações a respeito do tema deste estudo, entretanto tal discussão não se estanca ao finalizar esta análise, pelo contrário, há discussões plausível sobre o imaginário que podem contribuir, além do processo formativo, para a construção da identidade profissional docente a partir de temáticas que emergem do cotidiano escolar.

\section{EMBASAMENTO TEÓRICO}

Primar por uma definição teórica, requer do pesquisador uma investigação minuciosa para adentrar a conceitos específicos, como o caso desse estudo. Para tratar sobre o conceito de imaginário recorremos a Castoriadis (1982), o mesmo enfatiza a 
subjetividade como relação ao simbólico e o utiliza para significar as manifestações inerentes a cada pessoa.

Corroborando, Vygotski (1998), afirma que o sistema simbólico é representado pela linguagem dos seres humanos. Consequentemente, Castoriadis (1982, p. 409) afirma que: "as significações imaginárias sociais nos colocam diante de um modo de ser primário, originário, irredutível [...]" e que é de responsabilidade incidir a partir dele mesmo, não o subjugar a esquemas evidentes antecipadamente expostos.

Destarte, o imaginário se constitui apoiado a simbolismo já existente. Por isso, o imaginário e o simbolismo expressam relação de dependência, para Castoriadis (1982 p.141), o simbólico é "a maneira de ser sob a qual se constitui a instituição". O autor também salienta que as condições sociais-históricas apresentadas pertencem ao simbólico.

As circunstâncias sociais-históricas se traduzem por atos reais, individuais ou coletivos; trabalho, consumo, natalidade e os inumeráveis produtos materiais que pertencem à sobrevivência da sociedade, não são símbolos, porém, são impossíveis fora de uma rede simbólica. O simbólico, segundo Castoriadis (1982), além de ser encontrado incialmente na linguagem, é encontrado também nas circunstancias sociais-históricas que constituem uma rede simbólica, melhor, ligam os símbolos e os significados, fazendo-os valer naquele contexto.

Barbier (1984), afirma e que o conceito de imaginário tem significados diferentes para cada pessoa. Para alguns, pode significar uma produção de fantasias, de imagens deslumbrantes que transportam a pessoa para longe da sua realidade cotidiana, como uma força que estabelece a construção da identidade do sujeito. No entanto, designa a inserção da atividade imaginativa individual em um fenômeno coletivo. Ou seja, "os imaginários são referências específicas no vasto sistema simbólico que produz toda coletividade e através do qual ela se percebe, se divide e elabora suas finalidades". (BACZKO, 1984, p. 27).

Segundo Castoriadis (1982, p.144), "um símbolo não se impõe como necessidade natural", porém, priva-se da referência do real. Consequentemente, o simbolismo nega sua neutralidade, e, assim, constitui-se a linguagem que tem por finalidade atribuir os sentidos. Segundo o autor, a constituição social, está diretamente ligada com a liberdade, ou seja, participando ativamente das relações sociais-históricas entre significantes e 
significados, os quais não são previstos. Castoriadis (1982) apresenta o termo imaginário da seguinte forma:

[...] falamos de imaginário quando queremos falar de alguma coisa inventada - quer se trate de uma invenção, (uma história imaginada em todas as suas partes) ou de um deslizamento, de um deslocamento de sentido, onde símbolos já disponíveis são investidos de outras significações que não suas significações normais ou canônicas (p.154).

As relações entre o simbólico e o imaginário, nas palavras do autor, estabelecem a obviedade dos fatos para sair do abstrato, “o imaginário deve utilizar o simbólico, não somente para expressar o que é óbvio, mas para representar um conceito porque há problemas reais que os homens não conseguem resolver" (CASTORIADIS, 1982, p.162). Ainda, é preciso discorrer que o imaginário docente é organizado de acordo com os seus contextos, os quais se alicerçam em verdades constituídas que podem interferir em suas atividades pedagógicas. Vale ressaltar que é importante valorizar a subjetividade dos docentes, uma vez que os mesmos possam atribuir significados à prática, que é atravessada, segundo Castoriadis (1982), pelos desejos, angústias, medos, anseios, enfim, é marcada pela identidade docente.

Segundo Rey (2003), o conceito de Imaginário é entendido como a construção subjetiva dentro de uma perspectiva dialética complexa ${ }^{3}$. Castoriadis (1982) alimentou seus conceitos na perspectiva de duas fontes teóricas, Marx e Freud. Apesar das críticas,

\footnotetext{
${ }^{3} \mathrm{O}$ pensamento complexo e a tradição dialética, principalmente em sua formulação pedagógica freireana, enfatizam a educação enquanto processo permanente, cotidiano e coletivo pelo qual agimos e refletimos transformando a realidade de vida. Está focada na pedagogia do conflito, no princípio da incerteza, como forma de se estabelecer movimentos emancipatórios e políticos de transformação social. A visão holística está centrada no indivíduo, no alcançar a condição de ser humano integral e harmônico, o que reforça os pressupostos de existência de finalidades previamente estabelecidas na natureza e de relações ideais que fundamentam a pedagogia do consenso. Focaliza o ato educativo enquanto estímulo ao potencial transcendental que há em cada um de nós, com uma tendência a se aceitar a ordem social estabelecida como condição dada. $\mathrm{O}$ importante para essa vertente não é pensar processos educativos que associem mudança pessoal à mudança societária como polos indissociáveis na requalificação de nossa inserção na natureza e na dialetização entre subjetividade-objetividade; mas sim pensar a transcendência integradora, a transformação da pessoa pela ampliação da consciência, como caminho único para se obter a união com a natureza, subordinando a racionalidade à subjetividade. Em síntese, em termos das implicações sociopolíticas e de concepção do sujeito em sociedade e na natureza, Entendemos que a complexidade se presta mais a uma educação emancipadora porque favorece a reflexão do cotidiano, o questionamento e a transformação social, enquanto a holística, ao propor o consenso de uma pedagogia que visa a harmonia e a unidade, acaba por estimular a domesticação e a acomodação (LOREIRO, 2005, p. 1482)
} 
o autor aborda a subjetividade como questão essencial para as relações sociais, contudo o seu conceito central é o imaginário, o qual consequentemente se apresenta como condição subjetiva.

Durand (1989, p. 23), faz a seguinte observação: “o imaginário é a contínua troca que existe entre as pulsões subjetivas e assimiladoras e as intimações objetivas que emanam do meio cósmico e social”. O imaginário social é constituído por representações que um grupo expressa, ou a sociedade constitui a si mesma. Por isso, a classe social expressa suas concepções e justifica seus objetivos, tanto no preceito e regras admitidos quanto legal, de modo que afirme seu passado e imagina seu futuro.

Aponto a necessidade de estudar o imaginário social ao olhar a educação integral, ou seja, de ver e valorizar o docente ao ser histórico, cultural, com objetivos, mediador e construtor tanto de sua aprendizagem no social como a do estudante. Assim, o docente é composto por seus mitos e crenças, verdades, saberes constituídos em seu processo de formação e, a reflexão ressignificava. Diante do estudo, o imaginário social apresenta, possibilidade de um novo olhar, isto é, tem o potencial de ressignificar as aprendizagens e os significados subjetivos de cada um. Pois, a identidade profissional docente está em permanente construção juntamente com o processo de aprendizagem.

A práxis docente é interposta pela representação simbólica, já os significados estão na ênfase aos diferentes temas e situações abordados. As mesmas são enfrentadas de acordo com a subjetividade de cada um, que são construídas nos contextos sociais em que estamos inseridos. Castoriadis (1982) define como práxis aquilo que chamamos de uma atividade consciente. Para isso, ela se fundamenta no saber fragmentado, porque dá práxis surgem constantemente saberes que exigem novas conexões.

Os estudos realizados sobre o Imaginário Social, embasados em Castoriadis, (1982), definem a dimensão de como está e o que é a realidade, porém, acrescentam a possibilidade do novo. Dessa forma, a reflexão aqui realizada sobre o imaginário docente nos conduz a percepção de observar e extrair como os docentes veem a identidade sexual e de gênero dos estudantes. O imaginário, assim, se institui e representa uma possibilidade de ressignificar uma realidade que está posta [daquilo que está constituído, ou seja, a identidade do estudante] e uma que está sendo construída [neste caso, a identidade profissional docente].

Neste sentido, Castoriadis (1982) afirma que as significações precisam ser pensadas, não como um argumento irreal de um contexto real; mas como um sistema 
hierárquico de "conceitos"; como posição inicial do contexto histórico e do imaginário social, os quais se manifestam cada vez na sociedade. O autor diz que é preciso "[...] pensar um modo de ser à parte deste mundo - destes mundos - de significações em sua especificidade e sua originalidade, sem transformá-los em sujeitos de uma outra ordem" (CASTORIADIS, 1982, p. 413). Melhor dizendo, ao falar contexto e imaginário social, é preciso certa definição para compreender que não estamos nos referindo.

O docente constrói sua formação e identidade pautadas no âmbito de pensar a própria atuação. Diferentemente de uma concepção em que o docente se identificava unicamente pela sua área de atuação (biólogos, engenheiros, odontologista, médicos, administradores, etc.). O lugar em que é construída a sua identificação, a partir do conhecimento especializado, justifica-se pela sua formação para a prática profissional que está direcionada ao domínio científico. Assim sendo, diante do desafio imaginário, docentes acabam reagindo ao contexto social do aluno como algo que não lhes compete diretamente.

Dessa forma, esquece-se que alguns dos principais atos docentes é considerar a educação integral: o diálogo, a aproximação e as trocas. A construção das nossas imaginações e o sentido que atribuímos às nossas experiências docentes se dão a partir do confronto com as ideias alheias. Por isso, as apropriações realizadas durante a carreira docente fazem dos saberes, isto é, circulam pelas concepções imaginárias, assim divergem acerca de sensibilidade e capacidade de transformar $a$ forma de perceber o significado dos temas que emergem ao nosso redor.

A problematização do contexto educacional acontece por meio de sentidos e significados, através do imaginário docente e de todos os agentes que fazem da educação um espaço vivo e repleto de sentidos. Ao referenciar no texto a necessidade de ressignificar a mediação pedagógica pensadas para o docente formador, que ainda detém o imaginário alicerçado na investigação do que às necessidades formativas produzidas pela docência, concretiza sua identidade a moldura tradicional.

O imaginário, na concepção que foi abordada anteriormente por Castoriadis (1982), assume uma dimensão que é da ordem instituída daquilo que criamos e inventamos como pessoas, como profissionais e como sociedade, bem como aquilo que está por ser criado, inventado, como um movimento instituinte. Ao elevar o pensamento a lente do imaginário, percebemos que o processo da construção da identidade 
profissional emerge da relação que o docente estabelece com sua profissão, seus pares e, ao mesmo tempo, da construção simbólica, pessoal e interpessoal (GONÇALVES, 2000)

Nóvoa $(2000$, p.17) destaca que o processo identitário docente está na "maneira como cada um de nós ensina, está diretamente dependente daquilo que somos como pessoa". Nesse caso, os conhecimentos teóricos que o professor adquire na sua formação proporcionam situações em que ele reflita sobre sua própria ação, sua história de vida, suas memórias e outras representações contidas no seu imaginário, e por que ele ensina do modo como ensina. O mesmo autor admite que "a reflexão é uma dimensão decisiva da profissão docente, na medida em que a mudança e a inovação pedagógica estão intimamente dependentes deste pensamento reflexivo" (NÓVOA, 2000, p.17).

\section{METODOLOGIA}

O procedimento metodológico adotado para discutir a relação do imaginário com a constituição da identidade docente no âmbito escolar, inicialmente, utilizou uma revisão bibliográfica, a qual contou com a inclusão de estudos que descrevem sobre a problemática. Por meio de artigos científicos e livros, optou-se por trabalhar com abordagem qualitativa sobre a relação imaginaria com a identidade docente, buscando destacar a convivência plena e a dignidade humana perante temáticas que emergem.

Perante os aspectos mencionados o estudo se caracteriza como qualitativo, o qual Ludk e André consideram a "busca de questões muito específicas e pormenorizadas, preocupando-se com um nível da realidade que não pode ser mensurado e quantificado" (1986, p. 131). Por isso, os resultados do estudo qualitativo são obtidos de diversas maneiras, por meio de observação, reflexão, interpretação, etc. As investigações, neste estudo, tomam como referência as atividades humanas, as quais são influenciadas pelo contexto das práticas pedagógicas realizadas.

Em decorrência do aprofundamento teórico, foi necessário realizar uma revisão sucinta para este estudo, as bibliografias consultadas deram sustentação ao tema, portanto, o que se configura como uma revisão bibliográfica.

\section{ANALISE DE DADOS}


Esta etapa do estudo apresentou a constituição do imaginário e sua relação com a identidade docente de acordo com autores estudados, o sistema de significações constituídos por uma sociedade através das dimensões simbólicas constitui o imaginário. Diante dessa relação, o imaginário se apropria do simbólico para se expressar e apresentar as crenças, os mitos e as concepções culturais implícitas existentes no interior de cada pessoa.

A constituição do imaginário e da identidade profissional docente é uma temática amplamente discutida, sob diferentes posicionamentos teóricos. Os diálogos sobre esses temas são apresentados na sequência, como inspirações sobre a relevância da constituição do professorar, é o que Freire (1996) destaca, o comprometimento pedagógico é constituído pelo imaginário social.

Diante do fato mencionado, estudos sobre o imaginário possibilitam forma de pensar a constituição da identidade docente. Isso parte da ideia de que o docente constrói e (re) constrói a sua prática, e que a mesma tem a capacidade transformar, criar e construir. Dessa forma, pensar a profissão docente, a partir do imaginário, é pensar em significações, crenças, valores, ser e estar ao mesmo tempo em que o imaginário vem sendo uma fonte propulsora na produção de sentidos.

A legitimidade e o valor intrínseco representam seus conhecimentos e suas competências. As representações imaginárias, construídas pela identidade ultrapassam o espaço institucional e acompanham os docentes em sua vida pessoal e profissional. Logo, o processo se formação deve contribuir para criar hábitos de reflexão e de auto reflexão que são essenciais numa profissão que não se limita, unicamente, em matrizes científicas ou mesmo pedagógicas, mas que se define, a partir de referências pessoais, culturais e imaginárias.

No entanto, as tendências teóricas abrangem conhecimento, reflexão e dinâmica de trabalho, quando se refere ao imaginário docente e a constituição de sua identidade profissional, para o fazer educativo e o desenvolvimento das concepções, representações e consciências. Afirma Nóvoa (1992), que é preciso uma formação profissional com atuação e percepção das suas representações. Contudo, construir significados destaca a urgência de transformação, a qual envolve várias perspectivas sobre as convivências, com diferentes permutas entre os processos curriculares e pedagógicos entre o ensinar e o aprender. 
Para Freire (1996) há uma dimensão humana, ética e estética que não pode ficar à margem da profissionalização docente, por isso, à identidade profissional é construída na relação com outros profissionais, isto é, outras pessoas, outras, metodologias pedagógicas. Para Fossatti (2013, p. 179), “Antes de formar o educador ou o educando, se está formando a pessoa do educador ou do educando. Assim, o educador ou o educando sempre vêm associados com seu ser pessoa".

As reflexões apresentam a dimensão subjetiva docente, constitutiva de suas ações e relações pedagógicas (BERGAMASCHI e ALMEIDA, 2013). A concepção das ações e relações pedagógicas, evoluídas no âmbito das investigações sobre a subjetividade docente, essa, objetiva ir além da compreensão sobre a identidade profissional. Ser docente é assumir-se como profissional, é o fruto do saber próprio.

Diante da subjetividade, o imaginário docente, e os aspectos gerais da condição humana, emergem a necessidade de se pensar de forma diferenciada a identidade, para tanto, é preciso que a subjetividade seja colocada no centro das discussões. No entanto é "preciso olhar esse docente, considerando a sua subjetividade, ou seja, o seu imaginário instituído que é constituído a partir das relações que são ou que foram estabelecidas ao longo de seu percurso de formação" (MÜLLER, 2005, p. 74).

Ao discutir sobre as relações sociais, o imaginário cultural e historicamente construído, fundamenta Müller (2017) que o sistema de significados e constituídos pela sociedade. Diante do exposto, ao refletir sobre a identidade docente e sobre o imaginário social, os quais estão permeados por significados subjetivos nos diferentes espaços da sociedade, isto é, posicionamentos atravessados por assinalamento identitário. Nessa perspectiva, apresento a compreensão sobre o imaginário social das/os docentes que conduz o leitor a conhecer os entendimentos acerca da constituição da identidade profissional docente.

A identidade é definida como códigos sociais comportamentalistas exigidos pela sociedade. Em dialogo, o imaginário assume uma realidade específica. A relação dos saberes imaginários e representações sociais se apresentam, assim, de forma interacional com cada realidade vivenciada.

$\mathrm{Na}$ perspectiva contemporânea, a formação da identidade docente vem sendo entendida como uma ação de conhecimento técnico. No entanto, a busca pela crítica e pela reflexão é uma reconstrução permanente, a qual aponta novos caminhos para o 
desenvolvimento da educação, permeados pela inovação e pela capacidade de conhecer e reconhecer (CONTRERAS, 2002).

\section{CONSIDERAÇÕES FINAIS}

A constituição da identidade do/a professor/a principia, desde a fase inicial de sua formação, análise e o convívio com seus pares, da mesma forma ao iniciar a formação inicial com os/as professores/as e análise das práticas formativas destes, vai se expandindo e constituindo com as oportunidades que surgem no decorrer do exercício e da profissionalização, bem como a construção da identidade do/a professor/a, é um processo de constituição dos aspectos histórico, cultural e social.

De forma simples, procurei identificar as facetas que definem o imaginário com a cultura, tanto pessoal como profissional, ou seja, o trabalho pedagógico, o qual constitui a sua identidade com o compromisso social. Admitindo que essa é uma relação alta complexidade e um contínuo movimento.

À guisa de uma conclusão, percebo com este estudo que o imaginário está relacionado a subjetividade e se expressa na relação docente-discente, desenhando e redesenhando novas produções subjetiva nas ações e relações pedagógicas. Com isso, o docente representa o momento presente, resultado da confluência das configurações subjetivas constituídas em sua história, produzidas no confronto entre a subjetividade social e a subjetividade individual.

Os sentidos produzidos nas experiências vividas ao longo da trajetória docente, contribuem à identidade profissional, porém, essa constitui a base simbólico-emocional que promove a integração do imaginário com as ações realizadas.

Por fim, esperamos que esta pesquisa possa contribuir para a realização de novas investigações acerca de cenários desafiadores em torno da docência, envolvendo temas apresentados pelos discentes, apresentando uma reflexão sobre a dimensão e a atuação profissional. Essas reflexões, envolvem o imaginário individual e social que pode estar presente no fazer pedagógico dos profissionais de educação, caracterizando modos de ação específicas de sua identidade profissional docente. Por fim, a reflexão sobre a constituição da identidade docente está caracterizada pelo imaginário, por ideias, concepções, representações de pensamentos abstratos, mas também se contempla no real 
e efetivo que, por vezes, apresenta raízes culturais através das histórias pessoais e sociais anteriores ao contexto.

\section{REFERÊNCIAS}

BACZKO, Bronislaw. Los Imaginarios Sociales: memórias y esperanzas colectivas. Buenos Aires: Nueva Visión, 1984.

BARBIER, René. Sobre o imaginário. Trad. Márcia Lippincott da Costa e Vera de Paula. Em Aberto, Brasília, (61): 15-23, jan./mar. 1994.

BERGAMASCHI, M. A; ALMEIDA, D. B. Memoriais escolares e processos de iniciação à docência. Educação em Revista, Belo Horizonte, v. 29, n. 02, p. 15-41, 2013.

CASTORIADIS, Cornélius. A Instituição imaginária da sociedade. Rio de Janeiro: Paz e Terra, 1982.

CONTRERAS, José. A autonomia dos professores. São Paulo: Cortez, 2002.

DURAND, Gilbert. As estruturas antropológicas do imaginário. Lisboa: Presença, 1989.

FOSSATTI, Paulo. Perfil docente e produção de sentido. Canoas: Ed. Unilasalle, 2013.

FREIRE, Paulo. Pedagogia da Autonomia: saberes necessários à prática educativa. 25. ed. São Paulo: Paz e Terra, 1996.

GONÇALVES, José Alberto M. A carreira das professoras do ensino primário. In NÓVOA, António (org.). Vidas de professores. 2a ed. Portugal: Porto Editora, 2000.

LOUREIRO, Carlos Frederico Bernardo. Complexidade e dialética: contribuições à práxis política e emancipatória em educação ambiental Educ. Soc., Campinas, vol. 26, n. 93, p. 1473-1494, Set./Dez. 2005.

MÜLLER, Márcia Beatriz Cerutti. Surdez, gênero e sexualidade: um estudo sobre o imaginário social em uma escola de ensino fundamental bilíngue no sul do Brasil. Tese (Doutorado em Educação) - Programa de Pós-Graduação em Educação, Universidade La Salle, Canoas, 2017.

O imaginário docente na perspectiva da inclusão de alunos com necessidades educacionais especiais no ensino superior: um percurso de significados e ressignificações. Dissertação (mestrado em Educação) - Programa de Pós-graduação em Educação da Faculdade de Educação da Universidade Federal do Rio Grande do SulUFRGS, Porto Alegre, 2005.

LÜDKE, Menga; ANDRÉ, Marli E.D.A. Pesquisa em educação: abordagens qualitativas. São Paulo: EPU, 1986.

NÓVOA, Antônio. Os professores e a sua formação. Lisboa: Dom Quixote, 1992. 
(org.). Vidas de professores. 2a ed. Porto: Porto Editora, 2000.

REY, Fernando Gonzalez. Sujeito e Subjetividade. Trad. Raquel Souza Lobo Guzzo. São Paulo: Pioneira Thomson Learning, 2003.

TARDIF, Maurice. O trabalho docente: elementos para uma teoria da docência como profissão de interações humanas. 6. ed. Rio de Janeiro: Vozes, 2011.

VIGOTSKI, L.S. Pensamento e linguagem. São Paulo: Martins Fontes, 1998.

Recebido em: 01/06/2021

Aprovado em: 20/06/2021

Publicado em: 30/06/2021 